\title{
Current perspectives on treatment of hypertensive patients with chronic obstructive pulmonary disease
}

This article was published in the following Dove Press journal:

Integrated Blood Pressure Control

8 July 2013

Number of times this article has been viewed

\author{
Dipak Chandy' \\ Wilbert S Aronow ${ }^{2}$ \\ Maciej Banach ${ }^{3}$ \\ 'Division of Pulmonary, Critical Care \\ and Sleep, ${ }^{2}$ Division of Cardiology, \\ Department of Medicine, New \\ York Medical College, Valhalla, NY, \\ USA; ${ }^{3}$ Department of Hypertension, \\ Medical University of Lodz, \\ Lodz, Poland
}

\begin{abstract}
Systemic hypertension and chronic obstructive pulmonary disease (COPD) frequently coexist in the same patient, especially in the elderly. Today, a wide variety of antihypertensive drugs with different mechanisms of action are available to the prescribing physician. In addition, combination drugs for hypertension are becoming increasingly popular. Certain antihypertensive drugs can affect pulmonary function. Therefore the management of such patients can present therapeutic challenges. We have examined the literature pertaining to the use of antihypertensive drugs in patients with systemic hypertension and coexisting COPD. Although data are often limited or of poor quality, we have attempted to review and then provide recommendations regarding the use of all the specific classes of antihypertensive drug therapies including combination drugs in patients with COPD. The antihypertensive agents reviewed include diuretics, aldosterone receptor blockers, beta blockers, combined alpha and beta blockers, angiotensin-converting enzyme inhibitors, angiotensin II antagonists, calcium channel blockers, alpha-1 blockers, centrally acting drugs, direct vasodilators, and combinations of these drugs. Of these classes, calcium channel blockers and angiotensin II antagonists appear to be the best initial choices if hypertension is the only indication for treatment. However, the limited data available on many of these drugs suggest that additional studies are needed to more precisely determine the best treatment choices in this widely prevalent patient group.
\end{abstract}

Keywords: blood pressure, hypertension, COPD, treatment, antihypertensive drugs

\section{Introduction}

There is a high prevalence of both systemic hypertension and chronic obstructive pulmonary disease (COPD) in the adult population. COPD affects about $6 \%$ of the US adult population and is associated with high morbidity and mortality. ${ }^{1}$ However, the real prevalence may be much higher than $6 \%$, as half the patients with airflow limitation are asymptomatic, and thus COPD is not detected. ${ }^{2}$ Prevalence of COPD increases with age, from $3.2 \%$ among those aged $18-44$ years to $11.7 \%$ among those aged $\geq 65$ years. Systemic hypertension is much more prevalent than COPD, with $27.6 \%$ of the US adult population carrying the diagnosis. ${ }^{3}$ The prevalence of hypertension also increases with advancing age, with more than half of people 60-69 years of age and approximately three-fourths of those 70 years of age and older diagnosed with this condition. ${ }^{4}$

Data from the Medical Outcomes Study show that the prevalence of COPD in adult outpatients with systemic hypertension is similar to that in the general population. ${ }^{5}$ This would mean that there are about three million adults in the US with COPD who also have systemic hypertension. As a result, the management of hypertension in a patient
Correspondence: Wilbert S Aronow Cardiology Division, New York Medical College, Macy Pavilion, Room I38, Valhalla, NY 10595, USA

$\mathrm{Tel}+$ I 91449353 II

$\mathrm{Fax}+\mathrm{I} 9142356274$

Email wsaronow@aol.com 
with COPD is a common problem faced by a physician, especially when taking care of older adult patients.

Smoking tobacco is a major risk factor in the development of both systemic hypertension and COPD, and the Framingham Study has shown that smoking can increase the impact of hypertension as a risk factor in the development of cardiovascular disease. ${ }^{6,7}$ Epidemiological studies have suggested that ventilatory impairment measured by impaired forced expiration as seen in patients with COPD is an independent predictor of future cardiovascular events. ${ }^{8,9}$

The American College of Cardiology Foundation/ American Heart Association 2011 expert consensus document on hypertension in the elderly recommends that blood pressure should be lowered to less than 140/90 $\mathrm{mmHg}$ in adults younger than 80 years who are at high risk for cardiovascular events. ${ }^{10}$ On the basis of data from the Hypertension in the Very Elderly trial, ${ }^{11}$ these guidelines recommend that systolic blood pressure should be reduced to 140 to $145 \mathrm{mmHg}$, if tolerated, in adults aged 80 years and older. Since we have no reason to believe that treatment of patients with concomitant COPD should have different therapeutic targets than for other hypertensive patients, patients with COPD and hypertension should be treated according to these guidelines. ${ }^{10,12-17}$

Today, a wide variety of antihypertensive drugs with different mechanisms of action are available to physicians. Some antihypertensive drugs can have an adverse impact on pulmonary function and therefore the management of patients with COPD and hypertension can present certain therapeutic challenges. The goal of this review is to conduct an analysis of the literature and provide recommendations regarding antihypertensive drug treatment in patients with COPD.

\section{Search strategy}

We searched using electronic databases (MEDLINE [1966 to March 2013], EMBASE and SCOPUS [1965 to March 2013], and DARE [1966 to March 2013]). Additionally, abstracts from national and international cardiovascular meetings were searched. Where necessary, the relevant authors were contacted to obtain further data. The main data search terms were "antihypertensive drugs," "blood pressure," "COPD," "hypertension," "therapy," and "treatment."

\section{Review of specific classes of antihypertensive agents}

A large number of drugs are currently available to treat hypertension. Table 1 provides a list of the commonly used antihypertensive classes.
Table I Oral antihypertensive classes

\begin{tabular}{ll}
\hline Class & Examples \\
\hline Thiazide diuretics & Hydrochlorothiazide, chlorthalidone \\
Loop diuretics & Furosemide, bumetanide, torsemide \\
Potassium-sparing diuretics & Amiloride, triamterene \\
Aldosterone receptor blockers & Spironolactone \\
Cardioselective beta blockers & Metoprolol, nebivolol, bisoprolol \\
Noncardioselective beta & Propranolol \\
blockers & \\
Beta blockers with intrinsic & Pindolol, acebutolol \\
sympathomimetic activity & \\
Combined alpha and beta & Carvedilol, labetalol \\
blockers & \\
Angiotensin-converting enzyme & Captopril, enalapril, lisinopril, \\
inhibitors & ramipril \\
Angiotensin II antagonists & Candesartan, losartan, valsartan \\
Calcium channel blockers: non- & Diltiazem, verapamil \\
dihydropyridines & \\
$\begin{array}{l}\text { Calcium channel blockers: } \\
\text { dihydropyridines }\end{array}$ & Amlodipine, felodipine, nifedipine \\
Alpha-I blockers &
\end{tabular}

\section{Thiazide diuretics}

Based on the findings in the Antihypertensive and Lipid-Lowering Treatment to Prevent Heart Attack Trial (ALLHAT) ${ }^{18}$ the Seventh Report of the Joint National Committee on Prevention, Detection, Evaluation, and Treatment of High Blood Pressure (JNC 7) and others have concluded that low-dose thiazides should be used as the initial drug treatment of most patients with uncomplicated hypertension. ${ }^{6,18}$ There is a dearth of good outcome data from clinical studies designed to examine the effects of thiazide diuretics used as antihypertensive agents in patients with COPD. However, a recent study of patients with hypertension and COPD requiring two antihypertensive drugs, combination therapy that included a thiazide diuretic was associated with a significantly lower risk of hospitalization for congestive heart failure (CHF) among patients without a prior diagnosis of CHF. ${ }^{19}$ This study was a retrospective cohort of Veterans Administration Medical Center patients. ${ }^{19}$ The use of a thiazide diuretic in combination therapy in this study was not associated with a difference in risk of COPD exacerbations.

Thiazide diuretics have no adverse effect on airway function and can be used effectively in patients with COPD. ${ }^{20}$ However, the potential for serious hypokalemia must be recognized. ${ }^{21}$ This problem is related to the ability of inhaled beta- 2 receptor agonists like albuterol to drive potassium into the cells, and of oral corticosteroids, which 
are used for COPD exacerbations, to slightly increase urinary potassium excretion. ${ }^{22}$ In patients with COPD and chronic hypercapnia, there is another potential problem with the use of thiazide diuretics. This is the metabolic alkalosis induced by thiazide diuretics, which can suppress the ventilatory drive, potentially worsening the degree of hypoxemia and hypercapnia. ${ }^{23}$ With careful monitoring of electrolyte, hypercapnia, and oxygen levels, the use of thiazide diuretics is probably safe. Hypokalemia from thiazides is dose-dependent.

Thus, overall, it is probably safe to administer low doses of thiazide diuretics to nonedematous hypertensive patients with COPD. Low-dose treatment may be both effective and less likely to cause undesirable side effects such as hypokalemia and metabolic alkalosis.

\section{Loop diuretics}

Among patients with normal renal function, loop diuretics have a lesser antihypertensive effect than the thiazide diuretics. This may be related to the shorter duration of action of most loop diuretics when compared to the thiazides. However, loop diuretics may be useful in patients with COPD who have resistant hypertension, are volume overloaded, and have an estimated glomerular filtration rate of $<30 \mathrm{~mL} / \mathrm{min} / \mathrm{m}^{2}$. In addition, inhaled furosemide has shown some early promise as a dyspnea-relieving intervention in COPD. ${ }^{24}$

Patients with COPD who have chronic respiratory acidosis or are receiving corticosteroids or beta-agonists and do get treated with potassium-wasting loop diuretics should undergo close monitoring of electrolyte levels and be considered for therapy with potassium supplements. In addition, these drugs can increase hematocrit as well as lead to hemodynamic compromise in patients who are preload dependent in the setting of right heart failure.

\section{Potassium-sparing diuretics}

The potassium-sparing diuretics triamterene and amiloride have minimal antihypertensive effect and are not widely used as initial therapy for primary hypertension. ${ }^{25}$ However, these drugs may provide some antihypertensive benefit when added to multidrug regimens in patients with resistant hypertension. ${ }^{26}$ There are no specific contraindications or concerns about the use of these drugs in patients with COPD.

\section{Aldosterone receptor blockers}

Aldosterone receptor blockers can provide significant antihypertensive benefit when added to multidrug regimens in patients with resistant hypertension. ${ }^{27,28}$ These drugs have a clear role to play in patients with established heart failure; in addition, they may play a role in preventing the development of heart failure in patients with hypertension as suggested by a mouse study. ${ }^{29}$ There are no specific contraindications or concerns about the use of these drugs in patients with COPD. Spironolactone should be used as an add-on agent for treatment of resistant hypertension in patients with COPD.

\section{Beta blockers}

Adrenergic receptors of airway smooth muscle are primarily of the beta- 2 subtype. ${ }^{30}$ Beta- 2 receptor activation by beta- 2 agonists like albuterol causes bronchodilation by increasing adenylyl cyclase activity and inhibiting the cholinergic pathway. Therefore, nonselective beta blockers like propranolol can cause bronchoconstriction in susceptible individuals. ${ }^{31}$ As a result, the safety of beta blocker therapy in patients with COPD has been a common and longstanding concern. Traditional dogma has stated that beta blockers are contraindicated in COPD because of their bronchoconstrictive properties and "competition" with beta- 2 agonists. ${ }^{32}$ Therefore many physicians have avoided prescribing beta blockers in patients with COPD. ${ }^{33,34}$

However, selective beta-1 blockers like atenolol and metoprolol, which have a 20-fold greater affinity for beta-1 receptors than beta-2 receptors, are less likely to induce bronchoconstriction. A meta-analysis concluded that, in patients with COPD, single-dose or long-term treatment with selective beta blockers did not have a significant effect on forced expiratory volume in 1 second $\left(\mathrm{FEV}_{1}\right)$, beta-agonist response, inhaler use, or respiratory symptoms. ${ }^{35}$ Even in patients with COPD who had reactive airway disease, the use of selective beta blockers was only associated with a small decrease in $\mathrm{FEV}_{1}$ and a similar small increase in beta-agonist response with the first dose, both of which normalized with continued treatment. ${ }^{36}$ Cardioselective beta- 1 blockers such as metoprolol, bisoprolol, or nebivolol may be beneficial in COPD. Atenolol does not reduce cardiovascular events in patients with hypertension. Nonselective beta blockers such as propranolol may induce bronchospasm and should not be used in patients with COPD. Beta blockers with intrinsic sympathomimetic activity cause less reduction in pulmonary function tests than propranolol but have not been compared to cardioselective agents.

There is good evidence that the use of beta blockers reduces mortality in post-myocardial infarction patients with COPD or those undergoing major vascular surgery. ${ }^{37}$ There is also some evidence that the use of beta blockers 
in patients with COPD may actually reduce the risk of exacerbations and improve survival. ${ }^{38}$ However, a recent time-dependent analysis from Sweden suggests that beta blockers decrease survival in oxygen-dependent COPD. ${ }^{39}$ Similarly, in a randomized, double-blind, crossover trial, cardioselective beta blockers worsened airway obstruction in COPD patients. ${ }^{40}$ Formgren reported that the cardioselectivity of certain beta blockers can be lost at higher doses. ${ }^{41}$

Among the cardioselective beta blockers, bisoprolol may have the least effect on pulmonary function in patients with COPD. ${ }^{42,43}$ These studies show that treatment with atenolol produced a statistically significant increase in airway resistance when compared to bisoprolol and placebo. However, neither atenolol nor bisoprolol produced any significant changes in the more commonly used parameters of pulmonary function such as peak expiratory flow rate (PEFR), FEV ${ }_{1}$, and forced vital capacity (FVC).

Nebivolol is also an effective alternative in COPD patients. ${ }^{44-46}$ Nebivolol is a third-generation beta-adrenergic receptor antagonist with high beta-1 selective adrenergic receptor antagonism and vasodilating properties that induces a substantial decrease of arterial pressure in hypertensive subjects while preserving their left ventricular function. Respiratory effects of nebivolol have been widely investigated in animal models, in healthy volunteers, and in clinical trials carried out on patients suffering from bronchial asthma and COPD. ${ }^{44-46}$ In contrast to older compounds, nebivolol, which modulates the endogenous production of nitric oxide and affects oxidative cascade, proved clinically well tolerated in terms of respiratory outcomes in this type of subject. Moreover, due to the substantial dissociation between its cardiac and pulmonary activity, nebivolol confirmed a very good safety profile when regularly administered to hypertensive subjects with obstructive respiratory comorbidities. $^{44-46}$

Therefore, despite some conflicting data, selective beta-1 blockers appear to be relatively safe to use as an antihypertensive in stable COPD patients with irreversible or partially reversible airway obstruction and may in fact have some other additional benefits. However, if time permits, it would be safer to start a beta blocker at a small dose and carefully monitor for side effects as the dose is increased. During such initiation, patients with COPD should be carefully monitored for new symptoms (eg, dyspnea, exercise intolerance, cough) or changes in medication-use patterns (eg, increased need for a beta-agonist inhaler) that should then prompt reevaluation about the use of the drug. In a similar vein, the safety of starting beta blocker therapy in a patient during an exacerbation of COPD is not known, and so these agents should not be used during an exacerbation if hypertension is the only indication.

It needs to be emphasized that atenolol, despite its relatively safe profile in COPD patients, has very limited effectiveness in the treatment of hypertension, including a small or even negative influence on central blood pressure, arterial stiffness (pulse pressure), vascular resistance/ remodeling, and prevention of target organ damage, and therefore should be avoided. ${ }^{46,47}$

\section{Beta blockers with intrinsic sympathomimetic activity (ISA)}

There is evidence that treatment with beta blockers with ISA is associated with downregulation of beta- 2 receptors. ${ }^{48}$ This is consistent with data from an analysis that shows that continued treatment with beta-1 blockers with ISA did not produce the increase in beta- 2 agonist response that was seen with beta- 1 blockers without ISA. ${ }^{49}$

These agents decrease blood pressure and systemic vascular resistance, while the heart rate and cardiac output at rest are maintained. Beta blockers with ISA may therefore be used in clinical situations where non-ISA beta blockers are relatively contraindicated, such as sinus bradycardia, sick sinus syndrome, and Raynaud-like symptoms.

While it has been demonstrated that beta blockers with ISA, such as pindolol, have a less marked effect on pulmonary function than nonselective beta blockers without ISA, such as propranolol, there is no data comparing these drugs to beta-1 selective blockers without ISA. Therefore, the recommendations regarding the use of these drugs for the treatment of hypertension in patients with COPD have to be similar to those made above regarding the use of beta blockers.

\section{Combined alpha and beta blockers}

Recent experience indicates that combined nonselective beta and alpha blockade with carvedilol is well tolerated in patients with COPD who do not have reversible airway obstruction. Alpha-adrenergic blockade may promote mild bronchodilation that offsets nonselective beta blockadeinduced bronchoconstriction in patients with obstructive airway disease. ${ }^{50,51}$

The effect of carvedilol on lung function was compared to the selective beta blockers metoprolol and bisoprolol in 
35 patients with COPD and heart failure. $\mathrm{FEV}_{1}$ was lowest with carvedilol and highest with bisoprolol (carvedilol 1.85 [95\% confidence interval (CI): 1.67-2.03]; metoprolol 1.94 [95\% CI: 1.73-2.14]; bisoprolol 2.0 [95\% CI: 1.79-2.22]), although the 6-minute walk distance was not different. ${ }^{52}$ On the other hand, in a report of 14 patients with COPD treated with carvedilol $25 \mathrm{mg}$ twice daily for heart failure, no changes were noted in $\mathrm{FEV}_{1}$, vital capacity, or peak oxygen consumption with exercise. ${ }^{53}$ Similarly, labetalol up to $1200 \mathrm{mg} /$ day caused no significant changes in $\mathrm{FEV}_{1}$ or forced expiratory flow (FEF 25\%-75\%) in a small series of eleven patients with COPD and hypertension. ${ }^{54}$

All current evidence on combined nonselective beta and alpha blockade is observational or based on small studies. It is not yet clear whether this class of beta blockers is better tolerated due to the alpha blockade or merely because the nonselective beta blockers themselves are well tolerated. In view of the fact that not enough is known about their effect on respiratory function, nonselective agents that include alpha-adrenergic blockade should probably not be considered as an antihypertensive in a patient with COPD. ${ }^{55}$ However, carvedilol can be considered if such a patient has coexisting heart failure. The evidence is weaker for use of carvedilol and labetalol in patients with COPD than it is for use of cardioselective agents or beta blockers with intrinsic sympathomimetic activity.

\section{Angiotensin-converting enzyme (ACE) inhibitors}

The most common side effect of therapy with ACE inhibitors is cough, which develops in $5 \%-20 \%$ of patients. ${ }^{56}$ The cough is typically described as dry, irritating, and persistent, but rarely productive. The possibility that this cough may represent an asthma equivalent has been suggested by the demonstration of bronchial hyperresponsiveness in some affected patients, but this has not been a consistent finding. ${ }^{57,58}$

On the other hand, one study found that prior use of ACE inhibitors was associated with decreased mortality in older COPD patients hospitalized for exacerbation. ${ }^{59}$ There is also some emerging evidence that ACE inhibition may have a beneficial effect on skeletal muscle function and cardiovascular comorbidity in COPD patients. ${ }^{60}$ There are some indications that increased renin-angiotensin-system activity may contribute to the pathogenesis and progression of COPD. A small study from Japan showed that captopril, at a dose of $25 \mathrm{mg}$, was associated with lower exertional pulmonary artery pressure, lower pulmonary vascular resistance, higher mixed venous oxygen saturation, and lower lactate levels in selected COPD patients. ${ }^{61}$

At present, and based on the available evidence, ACE inhibitors should probably not be used as first-line antihypertensive therapy in patients with COPD. However, these agents are certainly not contraindicated in these disorders as long as the clinician is aware of the relatively uncommon complication of worsening airflow obstruction. When it is desirable to block the renin-angiotensin system, administration of an angiotensin II antagonist may be a better alternative because ACE inhibitor treatment may cause harm.

\section{Angiotensin II antagonists}

Angiotensin II antagonists do not appear to induce cough. Furthermore, among patients with symptomatic asthma, one study found no increase in bronchial hyperreactivity with their use. $^{62}$ In a study from Germany, angiotensin II antagonists were well tolerated in patients with stage III and IV COPD, although they did not improve respiratory muscle strength or exercise capacity as had been anticipated. ${ }^{63}$ Analysis of a Canadian database showed that angiotensin II antagonists improved both cardiovascular and pulmonary outcomes, especially when combined with statins. ${ }^{64}$ Therefore, based on the relatively limited data available, it appears to be safe to use these agents to treat hypertension in patients with COPD.

\section{Calcium channel blockers: non-dihydropyridines}

The non-dihydropyridine calcium channel blockers are negative chronotropes, inotropes, and dromotropes. They should be used with caution in patients with heart failure and in combination with medications that produce similar hemodynamic effects. Therefore, these agents tend to be more commonly given for rate control in patients with atrial fibrillation or for control of angina than for isolated hypertension. Regardless, they can be used safely in patients with COPD.

\section{Calcium channel blockers: dihydropyridines}

Initially, the dihydropyridine calcium channel blockers were thought to be potentially harmful in patients with COPD by worsening ventilation-perfusion matching and increasing hypoxemia. ${ }^{65}$ A subsequent study confirmed a very mild 
worsening of hypoxemia, but this was more than offset by an improvement in central hemodynamics. ${ }^{66}$

These drugs have also been shown to be excellent agents for the treatment of hypertension in patients with asthma. They have the theoretical advantages of opposing muscle contraction in tracheobronchial smooth muscle and possibly reinforcing the bronchodilator effect of beta agonists. A number of studies have shown modest improvement or no significant clinical benefit of calcium antagonists in asthma. ${ }^{67-69}$ Based on all of the above, the dihydropyridine calcium channel blockers appear to be excellent agents for the treatment of hypertension in patients with COPD.

\section{Alpha-I blockers}

A megastudy of terazosin showed that it maintained its antihypertensive efficacy and was well tolerated by patients with COPD. ${ }^{70}$ Similarly, a study from Scotland concluded that doxazosin is an effective oral antihypertensive drug, which did not exacerbate preexisting airflow limitation in patients with COPD. ${ }^{71}$ Based on the above, it would appear that there are no specific concerns regarding the use of alpha-1 blockers as antihypertensives in patients with COPD. However, alpha-1 blockers are not front-line drugs for the treatment of hypertension.

\section{Central alpha-2 agonists and other centrally acting drugs}

Clonidine and other alpha-2 receptor agonists like methyldopa should be used with caution in asthmatics. While these agents do not change baseline air flow in asthmatics, they have been shown to increase bronchial reactivity to inhaled histamine. ${ }^{72}$

There is no safety data available regarding the use of these drugs in patients with COPD. However, clonidine has been used as a second-line agent for smoking cessation and so may be able to play a dual role in active smokers with hypertension and COPD..$^{73}$

\section{Direct vasodilators}

There is little specific information available regarding the use of direct vasodilators such as hydralazine in COPD. However, if an asthma-like reaction occurs with these drugs, one should always consider the possibility that the tartrazine dye within the drug preparation may be the culprit. In a small study, hydralazine was shown to increase minute ventilation, alveolar ventilation, and arterial partial pressure of oxygen when administered to patients with COPD. ${ }^{74}$ Based on the limited literature available, it appears that there are no specific safety concerns regarding the use of direct vasodilators as antihypertensives in patients with COPD.

\section{Combination drugs}

Most patients with hypertension require more than one antihypertensive drug to provide adequate hypertensive control. ${ }^{75}$ Table 2 provides a list of the commonly used combination drugs for hypertension. A recent study by Herrin et al concluded that, in patients with hypertension and COPD requiring two antihypertensive agents, combination therapy that included a thiazide diuretic was associated with a significantly lower risk of hospitalization for CHF in patients without a prior history of CHF. ${ }^{19}$ There is also evidence that giving two or more drugs in fixed-dose combinations improves adherence and reduces costs compared to singlepill formulations.

\section{Summary}

Although hypertension and COPD are commonly seen in the same patients, especially in the elderly, there is relatively little or poor data regarding the use of many antihypertensive drugs in such patients. We have summarized the information that is currently available about these drugs in this review, and Table 3 is an attempt to provide some recommendations regarding their use in patients with hypertension and COPD. If hypertension is the only indication for using these drugs, then, based on a review of the currently available data, dihydropyridine calcium channel blockers and angiotensin II antagonists appear to be the best initial choices, although there are limited data on the use of dihydropyridine calcium

Table 2 Possible combination drugs for hypertension

\begin{tabular}{ll}
\hline Combination type & Examples \\
\hline $\begin{array}{l}\text { ACE inhibitors and calcium channel } \\
\text { blockers }\end{array}$ & $\begin{array}{l}\text { Amlodipine-benazepril, } \\
\text { enalapril-felodipine } \\
\text { ACE inhibitors and diuretics }\end{array}$ \\
$\begin{array}{l}\text { Angiotensin II antagonists and } \\
\text { diuretics }\end{array}$ & Losartan-hydrochlorothiazide \\
Beta blockers and diuretics & Bisoprolol- \\
Centrally acting drug and diuretic & hydrochlorothiazide \\
& Methyldopa- \\
hiuretic and diuretic & Triamterene- \\
& hydrochlorothiazide \\
\hline
\end{tabular}

Abbreviation: ACE, angiotensin-converting enzyme. 
Table 3 Summary of comments and recommendations regarding use of antihypertensive agents in patients with chronic obstructive pulmonary disease

\begin{tabular}{|c|c|}
\hline Class & Comments/recommendations \\
\hline Thiazide diuretics & Low doses are probably effective and safe. \\
\hline Loop diuretics & $\begin{array}{l}\text { Should not be used as an antihypertensive except in patients with advanced renal } \\
\text { disease who do not respond to thiazide diuretics. }\end{array}$ \\
\hline Potassium-sparing diuretics & Not a first-line agent. Limited data but no specific contraindications. \\
\hline Aldosterone receptor blockers & Not a first-line agent. Limited data but no specific contraindications. \\
\hline Beta blockers & $\begin{array}{l}\text { Some conflicting data, but cumulative evidence supports safety. Historical } \\
\text { underutilization probably not justified. Probably not a first-line agent if } \\
\text { hypertension is the only indication. Propranolol and atenolol should not be used. }\end{array}$ \\
\hline Beta blockers with intrinsic sympathomimetic activity & Limited data but probably similar to beta blockers. \\
\hline Combined alpha and beta blockers & Should probably not be used if hypertension is the only indication. \\
\hline Angiotensin-converting enzyme inhibitors & Should not be used as a first-line agent because of the associated cough. \\
\hline Angiotensin II antagonists & Limited data but no safety concerns. \\
\hline Calcium channel blockers: non-dihydropyridines & Can be used safely. \\
\hline Calcium channel blockers: dihydropyridines & First-line agent. \\
\hline Alpha-I blockers & No safety concerns. \\
\hline Central alpha- 2 agonists and other centrally acting drugs & Limited data but there may be some safety concerns. \\
\hline Direct vasodilators & Limited data but no safety concerns. \\
\hline
\end{tabular}

channel blockers in the treatment of hypertension in patients with COPD. Low-dose thiazide diuretics can also be considered. However, more studies are clearly needed in order to provide greater clarity about the large number of antihypertensive drugs available to physicians today treating patients with both these conditions. ${ }^{76-78}$

\section{Disclosure}

The authors report no conflicts of interest in this work.

\section{References}

1. Centers for Disease Control and Prevention (CDC). Chronic obstructive pulmonary disease among adults - United States, 2011. MMWR Morb Mortal Wkly Rep. 2012;61(46):938-943.

2. Centers for Disease Control and Prevention. Chronic obstructive pulmonary disease surveillance-United States, 1971-2000. MMWR Survell Summ 2002;51(6):1-16.

3. Egan BM, Zhao Y, Axon RN. US trends in prevalence, awareness, treatment, and control of hypertension, 1988-2008. JAMA. 2010;303(20): 2043-2050.

4. Burt VL, Whelton P, Roccella EJ, et al. Prevalence of hypertension in the US adult population. Results from the Third National Health and Nutrition Examination Survey, 1988-1991. Hypertension. 1995;25: 305-313.

5. Wells KB, Stewart A, Hays RD, et al. The functioning and well-being of depressed patients. Results from the Medical Outcomes Study. JAMA. 1989;262(7):914-919.

6. Chobanian AV, Bakris GL, Black HR, et al; Joint National Committee on Prevention, Detection, Evaluation, and Treatment of High Blood Pressure. National Heart, Lung, and Blood Institute; National High Blood Pressure Education Program Coordinating Committee. Seventh report of the Joint National Committee on Prevention, Detection, Evaluation, and Treatment of High Blood Pressure. Hypertension. 2003;42(6):1206-1252.

7. Kannel WB, Hubert H, Lew EA. Vital capacity as a predictor of cardiovascular disease: the Framingham study. Am Heart J. 1983;105(2): 311-315.
8. Higgins M, Keller JB, Wagenknecht LE, et al. Pulmonary function and cardiovascular risk factor relationships in black and in white young men and women. The CARDIA Study. Chest. 1991;99(2):315-322.

9. Tockman MS, Comstock GW. Respiratory risk factors and mortality: longitudinal studies in Washington County, Maryland. Am Rev Respir Dis. 1989;140(3 Pt 2):S56-S63.

10. Aronow WS, Fleg JL, Pepine CJ, et al. ACCF/AHA 2011 expert consensus document on hypertension in the elderly: a report of the American College of Cardiology Foundation Task Force on Clinical Expert Consensus Documents. Developed in collaboration with the American Academy of Neurology, American Geriatrics Society, American Society for Preventive Cardiology, American Society of Hypertension, American Society of Nephrology, Association of Black Cardiologists, and European Society of Hypertension. J Am Coll Cardiol. 2011;57:2037-2114.

11. Beckett NS, Peters R, Fletcher AE, et al; HYVET Study Group. Treatment of hypertension in patients 80 years of age or older. $N$ Engl J Med. 2008;358:1887-1898.

12. Aronow WS. Hypertension guidelines. Hypertension. 2011;58: 347-348.

13. Banach M, Michalska M, Kjeldsen SE, Małyszko J, Mikhailidis DP, Rysz J. What should be the optimal levels of blood pressure: does the J-curve phenomenon really exist? Expert Opin Pharmacother. 2011;12: 1835-1844.

14. Banach M, Aronow WS. Should we have any doubts about hypertension therapy in elderly patients?: ACCF/AHA 2011 expert consensus document on hypertension in the elderly. Pol Arch Med Wewn. 2011;121:253-258.

15. Aronow WS, Banach M. Ten most important things to learn from the ACCF/AHA 2011 expert consensus document on hypertension in the elderly. Blood Press. 2012;21:3-5.

16. Banach M, Aronow WS. Hypertension therapy in the elderly-do we know the answers to all the questions? The status after publication of the ACCF/AHA 2011 expert consensus document on hypertension in the elderly. J Hum Hypertens. 2012;26:641-643.

17. Aronow WS. Ten key points from the American College of Cardiology Foundation/American Heart Association 2011 expert consensus document on hypertension in the elderly. Am J Therap. Epub July 15, 2011.

18. Appel LJ. The verdict from ALLHAT - thiazide diuretics are the preferred initial therapy for hypertension. JAMA. 2002;288(23):3039-3042. 
19. Herrin MA, Feemster LC, Crothers K, Uman JE, Bryson CL, Au DH. Combination antihypertensive therapy among patients with COPD. Chest. 2013;143(5):1312-1320.

20. Light RW, Chetty KG, Stansbury DW. Comparison of the effects of labetalol and hydrochlorothiazide on the ventilatory function of hypertensive patients with mild chronic obstructive pulmonary disease. Am J Med. 1983;75(4A):109-114.

21. Lipworth BJ, McDevitt DG, Struthers AD. Prior treatment with diuretic augments the hypokalemic and electrocardiographic effects of inhaled albuterol. Am J Med. 1989;86(6 Pt 1):653-657.

22. Wong CS, Pavord ID, Williams J, Britton JR, Tattersfield AE. Bronchodilator, cardiovascular, and hypokalaemic effects of fenoterol, salbutamol, and terbutaline in asthma. Lancet. 1990;336(8728): 1396-1399.

23. Bear R, Goldstein M, Phillipson E, et al. Effect of metabolic alkalosis on respiratory function in patients with chronic obstructive lung disease. Can Med Assoc J. 1977;117(8):900-903.

24. Raghavan N, Webb K, Amornputtisathaporn N, O'Donnell DE. Recent advances in pharmacotherapy for dyspnea in COPD. Curr Opin Pharmacol. 2011;11(3):204-210.

25. Heran BS, Chen JM, Wang JJ, Wright JM. Blood pressure lowering efficacy of potassium-sparing diuretics (that block the epithelial sodium channel) for primary hypertension. Cochrane Database Syst Rev. 2012;11:CD008167.

26. Brown MJ, Palmer CR, Castaigne A, et al. Morbidity and mortality in patients randomised to double-blind treatment with a long-acting calcium-channel blocker or diuretic in the International Nifedipine GITS study: Intervention as a Goal in Hypertension Treatment (INSIGHT). Lancet. 2000;356(9227):366-372.

27. Chapman N, Dobson J, Wilson S, et al; Anglo-Scandinavian Cardiac Outcomes Trial Investigators. Effect of spironolactone on blood pressure in subjects with resistant hypertension. Hypertension. 2007; 49(4):839-845.

28. Václavík J, Sedlák R, Plachy $\mathrm{M}$, et al. Addition of spironolactone in patients with resistant arterial hypertension (ASPIRANT): a randomized, double-blind, placebo-controlled trial. Hypertension. 2011;57(6):1069-1075.

29. Kuster GM, Kotlyar E, Rude MK, et al. Mineralocorticoid receptor inhibition ameliorates the transition to myocardial failure and decreases oxidative stress and inflammation in mice with chronic pressure overload. Circulation. 2005;111(4):420-427.

30. Carstairs JR, Nimmo AJ, Barnes PJ. Autoradiographic visualization of beta-adrenoceptor subtypes in human lung. Am Rev Respir Dis. 1985;132(3):541-547.

31. McGavin CR, Williams IP. The effects of oral propranolol and metoprolol on lung function and exercise performance in chronic airways obstruction. Br J Dis Chest. 1978;72(4):327-332.

32. Ling Y, Saleem W, Shee CD. Concomitant use of beta-blockers and beta2-agonists. Eur Respir J. 2008;31(4):905-906.

33. Egred M, Shaw S, Mohammad B, Waitt P, Rodrigues E. Under-use of beta-blockers in patients with ischaemic heart disease and concomitant chronic obstructive pulmonary disease. QJM. 2005;98(7):493-497.

34. Gottlieb SS, McCarter RJ, Vogel RA. Effect of beta-blockade on mortality among high-risk and low-risk patients after myocardial infarction. N Engl J Med. 1998;339(8):489-497.

35. Salpeter S, Ormiston T, Salpeter E. Cardioselective beta-blockers for chronic obstructive pulmonary disease. Cochrane Database Syst Rev. 2005;(4):CD003566.

36. Salpeter SR, Ormiston TM, Salpeter EE. Cardioselective beta-blockers in patients with reactive airway disease: a meta-analysis. Ann Intern Med. 2002;137(9):715-725.

37. van Gestel YR, Hoeks SE, Sin DD, et al. Impact of cardioselective betablockers on mortality in patients with chronic obstructive pulmonary disease and atherosclerosis. Am J Respir Crit Care Med. 2008;178(7): 695-700.

38. Rutten FH, Zuithoff NP, Hak E, Grobbee DE, Hoes AW. Beta-blockers may reduce mortality and risk of exacerbations in patients with chronic obstructive pulmonary disease. Arch Intern Med. 2010;170(10): $880-887$.
39. Ekström MP, Hermansson A, Ström KE. Effects of cardiovascular drugs on mortality in severe chronic obstructive pulmonary disease. Am J Respir Crit Care Med. 2013;187(7):715-720.

40. Dorow P, Thalhofer S, Bethge H, Disselhoff G, Wagner G. Long-term treatment of angina pectoris with bisoprolol or atenolol in patients with chronic obstructive bronchitis: a randomized, double-blind crossover study. J Cardiovasc Pharmacol. 1990;16 Suppl 5:S36-S44.

41. Formgren $H$. The effect of metoprolol and practolol on lung function and blood pressure in hypertensive asthmatics. Br J Clin Pharmacol. 1976;3(6):1007-1014.

42. Chatterjee SS. The cardioselective and hypotensive effects of bisoprolol in hypertensive asthmatics. J Cardiovasc Pharmacol. 1986;8 Suppl 11: S74-S77.

43. Dorow P, Bethge H, Tönnesmann U. Effects of single oral doses of bisoprolol and atenolol on airway function in nonasthmatic chronic obstructive lung disease and angina pectoris. Eur J Clin Pharmacol. 1986;31(2):143-147.

44. Cockcroft JR, Pedersen ME. $\beta$-blockade: benefits beyond blood pressure reduction? J Clin Hypertens (Greenwich). 2012;14(2):112-120.

45. Dal Negro R. Pulmonary effects of nebivolol. Ther Adv Cardiovasc Dis. 2009;3(4):329-334.

46. Bielecka-Dabrowa A, Aronow WS, Rysz J, Banach M. Current place of beta-blockers in the treatment of hypertension. Curr Vasc Pharmacol. 2010;8(6):733-741.

47. Stepień M, Banach M, Jankowski P, Rysz J. Clinical implications of non-invasive measurement of central aortic blood pressure. Curr Vasc Pharmacol. 2010;8(6):747-752.

48. Basso A, Piantanelli L, Cognini G, Giunta S, Andreoni A, Paciaroni E. Acebutolol-induced decrease of mononuclear leukocyte betaadrenoceptors in hypertension. Pharmacology. 1985;31(5):278-283.

49. Jakubetz J, Schmuck S, Poller U, et al. Cardiac effects of betaadrenoceptor antagonists with intrinsic sympathomimetic activity in humans: beta1- and/or beta2-adrenoceptor mediated? J Cardiovasc Pharmacol. 1999;33(3):461-472.

50. Sirak TE, Jelic S, Le Jemtel TH. Therapeutic update: non-selective beta- and alpha-adrenergic blockade in patients with coexistent chronic obstructive pulmonary disease and chronic heart failure. $J \mathrm{Am}$ Coll Cardiol. 2004;44(3):497-502.

51. Kotlyar E, Keogh AM, Macdonald PS, Arnold RH, McCaffrey DJ, Glanville AR. Tolerability of carvedilol in patients with heart failure and concomitant chronic obstructive pulmonary disease or asthma. J Heart Lung Transplant. 2002;21(12):1290-1295.

52. Jabbour A, Macdonald PS, Keogh AM, et al. Differences between betablockers in patients with chronic heart failure and chronic obstructive pulmonary disease: a randomized crossover trial. $\mathrm{J} \mathrm{Am} \mathrm{Coll} \mathrm{Cardiol}$. 2010;55(17):1780-1787.

53. Guazzi M, Agostoni P, Matturri M, Pontone G, Guazzi MD. Pulmonary function, cardiac function, and exercise capacity in a follow-up of patients with congestive heart failure treated with carvedilol. Am Heart J. 1999;138(3 Pt 1):460-467.

54. George RB, Manocha K, Burford JG, Conrad SA, Kinasewitz GT. Effects of labetalol in hypertensive patients with chronic obstructive pulmonary disease. Chest. 1983;83(3):457-460.

55. Andrus MR, Loyed JV. Use of beta-adrenoceptor antagonists in older patients with chronic obstructive pulmonary disease and cardiovascular co-morbidity: safety issues. Drugs Aging. 2008;25(2):131-144.

56. Israili ZH, Hall WD. Cough and angioneurotic edema associated with angiotensin-converting enzyme inhibitor therapy. A review of the literature and pathophysiology. Ann Intern Med. 1992;117(3):234-242.

57. Bucknall CE, Neilly JB, Carter R, Stevenson RD, Semple PF. Bronchial hyperreactivity in patients who cough after receiving angiotensin converting enzyme inhibitors. Br Med J (Clin Res Ed). 1988;296(6615): 86-88.

58. Boulet LP, Milot J, Lampron N, Lacourcière Y. Pulmonary function and airway responsiveness during long-term therapy with captopril. JAMA. 1989;261(3):413-416.

59. Mortensen EM, Copeland LA, Pugh MJV, et al. Impact of statins and ACE inhibitors on mortality after COPD exacerbations. Respir Res. 2009; $10: 45$. 
60. Shrikrishna D, Astin R, Kemp PR, Hopkinson NS. Renin-angiotensin system blockade: a novel therapeutic approach in chronic obstructive pulmonary disease. Clin Sci (Lond). 2012;123(8):487-498.

61. Kanazawa H, Hirata K, Yoshikawa J. Effects of captopril administration on pulmonary haemodynamics and tissue oxygenation during exercise in ACE gene subtypes in patients with COPD: a preliminary study. Thorax. 2003;58(7):629-631.

62. Tanaka H, Teramoto S, Oashi K, et al. Effects of candesartan on cough and bronchial hyperresponsiveness in mildly to moderately hypertensive patients with symptomatic asthma. Circulation. 2001;104(3): 281-285.

63. Andreas S, Herrmann-Lingen C, Raupach T, et al. Angiotensin II blockers in obstructive pulmonary disease: a randomised controlled trial. Eur Respir J. 2006;27(5):972-979.

64. Mancini GB, Etminan M, Zhang B, Levesque LE, FitzGerald JM, Brophy JM. Reduction of morbidity and mortality by statins, angiotensinconverting enzyme inhibitors, and angiotensin receptor blockers in patients with chronic obstructive pulmonary disease. J Am Coll Cardiol. 2006;47(12):2554-2560.

65. Melot C, Hallemans R, Naeije R, Mols P, Lejeune P. Deleterious effect of nifedipine on pulmonary gas exchange in chronic obstructive pulmonary disease. Am Rev Respir Dis. 1984;130(4):612-616.

66. Bratel T, Hedenstierna G, Nyquist O, Ripe E. The use of a vasodilator, felodipine, as an adjuvant to long-term oxygen treatment in COLD patients. Eur Respir J. 1990;3(1):46-54.

67. Schwartzstein RS, Fanta $\mathrm{CH}$. Orally administered nifedipine in chronic stable asthma. Comparison with an orally administered sympathomimetic. Am Rev Respir Dis. 1986;134(2):262-265.

68. Ann Twiss M, Harman E, Chesrown S, Hendeles L. Efficacy of calcium channel blockers as maintenance therapy for asthma. Br J Clin Pharmacol. 2002;53(3):243-249.
69. Patakas D, Maniki E, Tsara V, Dascalopoulou E. Nifedipine treatment of patients with bronchial asthma. JAllergy Clin Immunol. 1987;79(6): 959-963.

70. Itskovitz HD. Alpha 1-blockade for the treatment of hypertension: a megastudy of terazosin in 2214 clinical practice settings. Clin Ther. 1994;16(3):490-504.

71. Biernacki W, Flenley DC. Doxazosin, a new alpha-1-antagonist drug, controls hypertension without causing airways obstruction in asthma and COPD. J Hum Hypertens. 1989;3(6):419-425.

72. Dinh Xuan AT, Matran R, Regnard J, Vitou P, Advenier C, Lockhart A. Comparative effects of rilmenidine and clonidine on bronchial responses to histamine in asthmatic subjects. Br J Clin Pharmacol. 1988;26(6): 703-708.

73. Crain D, Bhat A. Current treatment options in smoking cessation. Hosp Pract (1995). 2010;38(1):53-61.

74. Corriveau ML, Vu-Dinh Minh, Dolan GF. Long-term effects of hydralazine on ventilation and blood gas values in patients with chronic obstructive pulmonary disease and pulmonary hypertension. Am J Med. 1987;83(5):886-892.

75. Gradman AH, Basile JN, Carter BL, Bakris GL; American Society of Hypertension Writing Group. Combination therapy in hypertension. J Am Soc Hypertens. 2010;4(1):42-50.

76. Mathew J, Aronow WS, Chandy D. Therapeutic options for severe asthma. Arch Med Sci. 2012;8(4):589-597.

77. Sekhri V, Mehta N, Rawat N, Lehrman SG, Aronow WS. Management of massive and nonmassive pulmonary embolism. Arch Med Sci. 2012;8(6):957-969.

78. Barylski M, Małyszko J, Rysz J, Myśliwiec M, Banach M. Lipids, blood pressure, kidney - what was new in 2011? Arch Med Sci. 2011;7(6) 1055-1066.
Integrated Blood Pressure Control

\section{Publish your work in this journal}

Integrated Blood Pressure Control is an international, peer-reviewed open-access journal focusing on the integrated approach to managing hypertension and risk reduction. Treating the patient and comorbidities together with diet and lifestyle modification and optimizing healthcare resources through a multidisciplinary team approach constitute key

\section{Dovepress}

features of the journal. This journal is indexed on American Chemical Society's Chemical Abstracts Service (CAS). The manuscript management system is completely online and includes a very quick and fair peerreview system, which is all easy to use. Visit http://www.dovepress.com/ testimonials.php to read real quotes from published authors. 